\title{
Synthesis of 6-bromo-4-iodoquinoline
}

\section{Wenhui Wang ${ }^{1}$, Yuping Guo ${ }^{1}$ a $^{*}$, Linxiao Wang ${ }^{1}$, Yiqiang OuYang ${ }^{1}$, Qinqin Wang ${ }^{1}$, Wufu Zhu ${ }^{1, b^{\prime}}$}

${ }^{1}$ School of Pharmacy, Jiangxi Science \& Technology Normal University, Nanchang 330013, China

*aguoyp_2012@126.com, ${ }^{* b}$ zhuwufu-1122@163.com,

Keywords: Synthesis, 4-Bromoaniline, 6-bromo-4-iodoquinoline

\begin{abstract}
Bromo-4-iodoquinoline is an important intermediate for the synthesis of many biologically active compounds, such as GSK2126458. It was synthesized from 2,2-dimethyl-1,3dioxane-4,6-dione and 4-bromoaniline through five steps including cyclization reaction and substitution reaction. And the structures of 6-bromoquinolin-4-ol and 6-bromo-4-iodoquinoline were confirmed by ${ }^{1} \mathrm{H}$ NMR spectrum.
\end{abstract}

\section{Introduction}

6-Bromo-4-iodoquinoline is a kind of important intermediate in the synthesis of GSK2126458. Its synthetic method was reported in a large amount of literature. Liu Kun et al. synthesized 6-bromo-4-iodoquinoline based on triethylor thoformate, meldrum's acid and 4-bromoaniline, which were stirred together at room temperature. The product was cyclized in ether under argon at $210{ }^{\circ} \mathrm{C}$ to get 6-bromoquinolin-4-ol. Then reacted with $\mathrm{POCl}_{3}$ to obtain 6-bromo-4-chloroquinoline which was reacted with hydrochloric acid/ethyl ether to afford the hydrochloride. The hydrochloride was replaced by $\mathrm{NaI}$ in acetonitrile to obtain the title compound 6-bromo-4-iodoquinoline ${ }^{[1]}$. Synthetic method of Min Wang et al. is slightly different. Meldrum's acid and trimethyl orthoformate were refluxed for $3 \mathrm{~h}$, when the solution was cooled to $50{ }^{\circ} \mathrm{C}$, 4-bromoaniline in trimethyl orthoformate was added dropwise. The obtained product was added slowly to preheated $\mathrm{Ph}_{2} \mathrm{O}$ and heated at $250{ }^{\circ} \mathrm{C}$ for $15 \mathrm{~min}^{[2]}$. The steps of Chlorination and Iodination was similar to Liu Kun's. In other reports such as Wenjuan Zhang et al. and XI Ning et al., triethylorthoformate, meldrum's acid and 4-bromoaniline were stirred and refluxed in ethanol which is an solvent to furnish compound 5-(((4-bromophenyl)amino)methylene)-2,2-dimethyl-1,3-dioxane-4,6-dione. Afterwards, the compound was heated in $\mathrm{Ph}_{2} \mathrm{O}$ at $220{ }^{\circ} \mathrm{C}^{[3,4]}$. The remaining steps are similar to the previous. These synthetic route were shown in route $\mathbf{b}$ of scheme 1 .

There are some other synthetic methods of quinoline using other raw materials. Mugnaini Claudia et al. synthesized quinoline based on ethyl propiolate and 4-bromoaniline in methanol, the compound was cyclized in $\mathrm{Ph}_{2} \mathrm{O}$ at $280{ }^{\circ} \mathrm{C}^{[5]}$ (route a in scheme 1). Ma,Menglin's method was started from ethyl 3,3-diethoxypropanoate and 4-bromoaniline, then cyclized in $\mathrm{Ph}_{2} \mathrm{O}$ at $230{ }^{\circ} \mathrm{C}^{[6]}$ (route $\mathbf{c}$ in scheme 1). Ai Jeng Lin and REN,Pingda synthesized it from diethyl 2- (ethoxy methylene)malonate and 4-bromoaniline ${ }^{[7,8]}$ (route $\mathbf{d}$ in scheme 1). Duffy,Kevin J's method was started from ethoxyethene, diethyl malonate and 4-bromoaniline ${ }^{[9]}$ (route $\mathbf{e}$ in scheme 1).

In this study, Our synthetic method of 6-bromo-4-iodoquinoline was optimized based on the previous study. In the first step, the reaction was without solvent which is ethanol in other literature. Because during the reaction, ethanol was generated. And in the third step, the temperature was $190{ }^{\circ} \mathrm{C}$ in order to avoid the impurities. In this way, the yield was developed and the reaction time was shortened. 


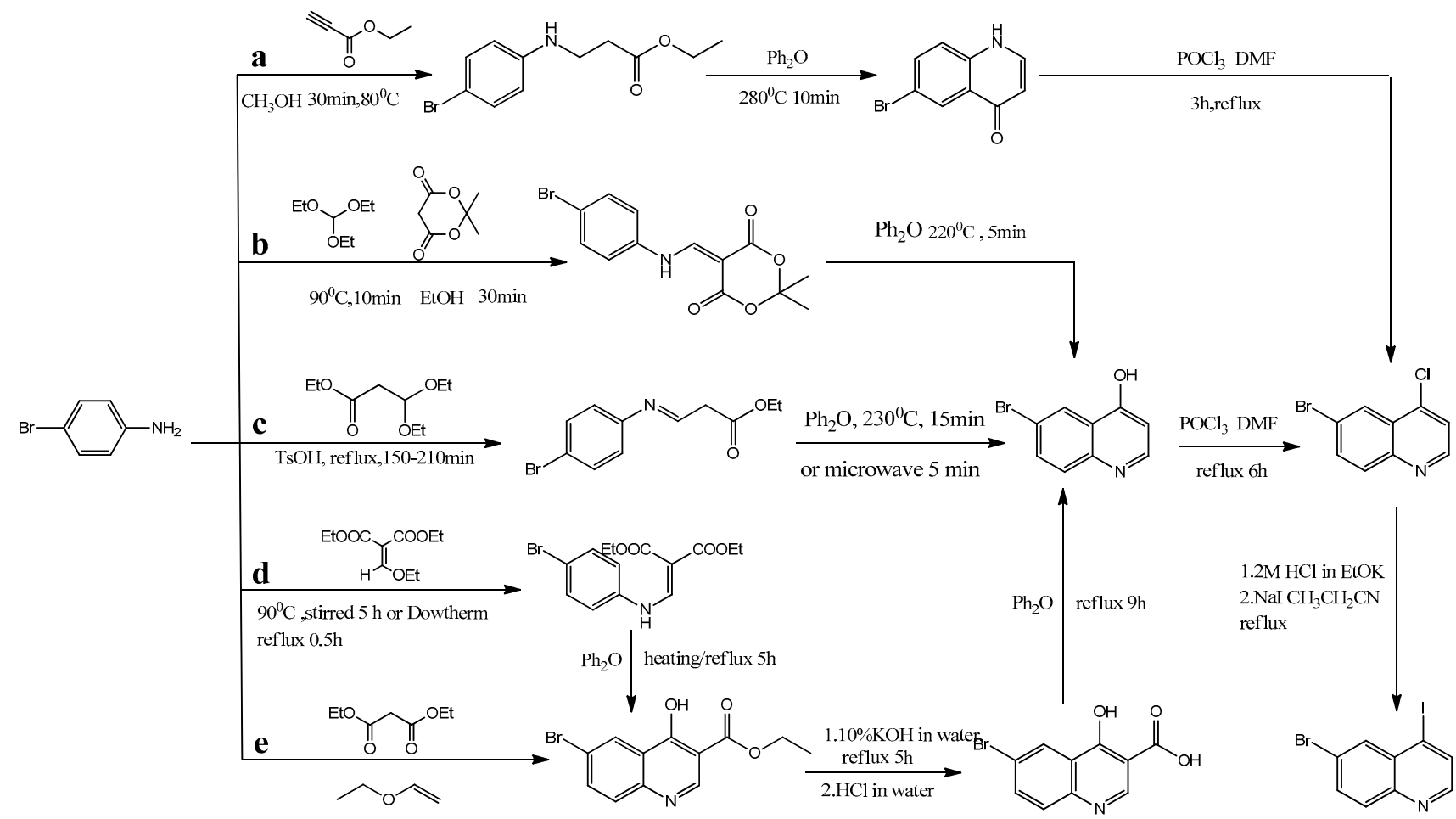

Scheme 1. The synthetic route of 6-bromo-4-iodoquinoline in other literature

\section{Materials and methods}

NMR spectra were performed using Bruker $500 \mathrm{MHz}$ spectrometers (Bruker Bioscience, Billerica,MA, USA) with TMS as an internal standard.All the materials were obtained from commercial suppliers and used without purification, unless otherwise specified.Yields were not optimized. TLC analysis was carried out on silica gel plates GF254 (Qindao Haiyang Chemical, China).

\section{Synthesis of compounds}

The structures and the synthetic route were shown in Scheme 2.<smiles>CC(C)(C)C=COC=C1C(=O)OC(C(C)(C)C)C(C)(C)OC1=O</smiles>

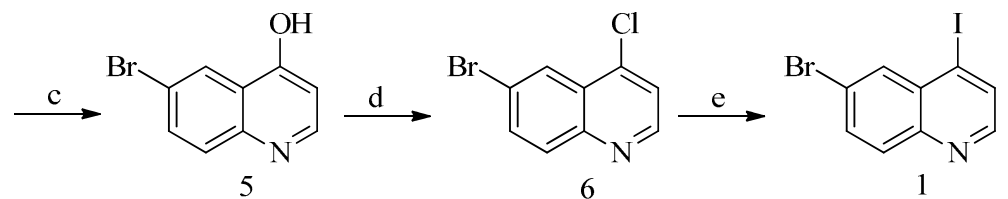

Scheme 2. The synthetic route of Compound 1

Reagents and conditions:(a) $105{ }^{\circ} \mathrm{C}$, Triethylorthoformate, $3 \mathrm{~h}$; (b) 4-bromoaniline, $\mathrm{C}_{2} \mathrm{H}_{5} \mathrm{OH}, 80{ }^{\circ} \mathrm{C}$, 3.5 h; (c) $\mathrm{Ph}_{2} \mathrm{O}, 190{ }^{\circ} \mathrm{C}, 10 \mathrm{~min}$; (d) $\mathrm{POCl}_{3}$, DMF, $110{ }^{\circ} \mathrm{C}, 3 \mathrm{~h}$; (e) THF, $\mathrm{HCl} / \mathrm{Et}_{2} \mathrm{O}, \mathrm{NaI}, \mathrm{CH}_{3} \mathrm{CN}$.

\section{5-(Ethoxymethylene)-2,2-dimethyl-1,3-dioxane-4,6-dione (4)}

Triethyl orthoformate $(225.25 \mathrm{~g}, 1.5 \mathrm{~mol})$ were added to meldrum's acid (36.028 g, $0.25 \mathrm{~mol})$. Heated to $105{ }^{\circ} \mathrm{C}$ and stirred for $3 \mathrm{~h}$. The mixture was cooled and poured into $200 \mathrm{~mL}$ petroleum 
ether in an ice bath for $30 \mathrm{~min}$, light yellow solid was precipitated, filtered off and dried to obtain the title compound (4) $(40.521 \mathrm{~g}, 80.98 \%)$.

\section{5-(((4-Bromophenyl)amino)methylene)-2,2-dimethyl-1,3-dioxane-4,6-dione (5)}

4-Bromoaniline (28.5123 g, $0.166 \mathrm{~mol})$ and 5-(ethoxymethylene)-2,2-dimethyl-1,3-dioxane-4,6dione (4) (31.8749 g, $0.098 \mathrm{~mol})$ was dissolved in ethanol $(480 \mathrm{~mL})$. Reflux at $80{ }^{\circ} \mathrm{C}$ for $3 \mathrm{~h}$. The reaction solution was cooled. Then the insoluble was filtered, washed with ethanol and dried to afford the title compound which was white powder (5) (51.8165 g, 99.73\%).

\section{6-Bromoquinolin-4-ol (6)}

Ether $(110.793 \mathrm{~g}, 0.65 \mathrm{~mol})$ as the solvent was preheated, then 5-(((4-bromophenyl)amino) methylene)-2,2-dimethyl-1,3-dioxane-4,6-dione (5) (10.110 g, $0.031 \mathrm{~mol})$ was slowly added into ether. Stirred at reflux for $10 \mathrm{~min}$. After the reaction was finished, the reaction solution was cooled to $50{ }^{\circ} \mathrm{C}$. And then the resulting mixture was added to petroleum ether slowly at room temperature, stirred for $10 \mathrm{~min}$. The precipitated solid was filtered, washed with ethyl acetate and dried to get the yellowish product (6) (4.163 g, 59.89\%). ${ }^{1} \mathrm{H}$ NMR (400MHZ, DMSO-d 6 ): $\delta 8.15(\mathrm{~d}, \mathrm{~J}=2.4 \mathrm{~Hz}, 1 \mathrm{H})$, $7.95(\mathrm{~m}, 1 \mathrm{H}), 7.78(\mathrm{~m}, 1 \mathrm{H}), 7.51(\mathrm{~d}, \mathrm{~J}=9.2 \mathrm{~Hz}, 1 \mathrm{H}), 6.0(\mathrm{~d}, \mathrm{~J}=7.2 \mathrm{~Hz}, 1 \mathrm{H})$.

\section{6-Bromo-4-chloroquinoline (7)}

$\mathrm{POCl}_{3}(25 \mathrm{~mL})$ was added to 6-bromoquinolin-4-ol (6) $(2.023 \mathrm{~g}, 0.009 \mathrm{~mol})$ dropwise, then two drops of DMF was added to the mixture. Stirred for $5 \mathrm{~min}$ at room temperature, then refluxed at $110{ }^{\circ} \mathrm{C}$ for $3 \mathrm{~h}$. Most of $\mathrm{POCl}_{3}$ was distilled off, the remaining oil was slowly added to ice water, stirred for $30 \mathrm{~min}$. The solution was adjusted to $\mathrm{pH}$ 5-6 with $\mathrm{NaHCO}_{3}$ saturated solution. Extracted with dichloromethane. The organic layer was washed twice with water, then dried with anhydrous sodium sulfate and filtered. The filtrate was distilled to afford yellowish product (7) (1.779 g, 81\%).

\section{6-Bromo-4-iodoquinoline (1)}

6-bromo-4-chloroquinoline (7) (0.204 g, $0.00084 \mathrm{~mol})$ was dissolved in THF $(10 \mathrm{~mL})$, then $\mathrm{HCl} / \mathrm{EtOH}(3.53 \mathrm{~g} / 240 \mathrm{~mL}, 80 \mathrm{~mL})$ was added to the solution dropwise, stirred for $30 \mathrm{~min}$ at room temperature. The mixture was distilled under reduced pressure to obtain the gray hydrochloride. The hydrochloride $(0.100 \mathrm{~g}, 0.00036 \mathrm{~mol})$ and $\mathrm{NaI}(1.638 \mathrm{~g}, 0.01 \mathrm{~mol})$ was dissolved in acetonitrile $(40 \mathrm{~mL})$, and refluxed at $100{ }^{\circ} \mathrm{C}$ for $32 \mathrm{~h}$. The reaction liquid was cooled, distilled to get yellow powder. $\mathrm{K}_{2} \mathrm{CO}_{3}$ saturated solution $(20 \mathrm{~mL})$ and $\mathrm{NaSO}_{3}$ saturated solution $(8 \mathrm{~mL})$ was added to the powder, stirred for $10 \mathrm{~min}$ and filtered to afford the khaki product (1) $(0.099 \mathrm{~g}, 35.2 \%) .{ }^{1} \mathrm{H}$ NMR (400 MHz, DMSO) $\delta 8.54(\mathrm{~d}, J=4.5 \mathrm{~Hz}, 1 \mathrm{H}), 8.24(\mathrm{~d}, J=4.5 \mathrm{~Hz}, 1 \mathrm{H}), 8.16(\mathrm{~s}, 1 \mathrm{H}), 7.98$ (s, $2 \mathrm{H})$.

\section{Conclusions}

In conclusion, 6-bromo-4-iodoquinoline (1) was synthesized from Triethyl orthoformate, meldrum's acid and 4-bromoaniline through five steps including cyclization reaction and the substitution reaction. The synthetic method of (1) was optimized by changing temperature and solvent of the reaction. So the synthetic method can be used to synthesize quinoline derivatives.

\section{Acknowledgments}

We gratefully acknowledge the generous support provided by The National Natural Science Funds (No.80140357), Project supported by the Natural Science Foundation of Jiangxi Province (No.20142BAB215020) and Program of Key Laboratory of Drug Design and Optimization, Jiangxi 
Science \& Technology Normal University (300098010306).

\section{References}

[1] Liu Kun, Li Wei, Fan Houxing, et al. Synthesis of Antitumor Candidate GSK2126458, J. Chemical Industy Times, 24 (2010) 40-43.

[2] Min Wang, Mingzhang Gao, Kathy D. Miller, et al. $\left[{ }^{11} \mathrm{C}\right] \mathrm{GSK} 2126458$ and $\left[{ }^{18} \mathrm{~F}\right] \mathrm{GSK} 2126458$, the first radiosynthesis of new potential PET agents for imaging of PI3K and mTOR in cancers, J. Bioorganic \& Medicinal Chemistry Letters, 22(2012) 1569-1574.

[3] Wenjuan Zhang, Zhi Li, Meng Zhou, et al. Synthesis and biological evaluation of 4-(1,2,3-triazol-1-yl)coumarin derivatives as potential antitumor agents, J. Bioorganic \& Medicinal Chemistry Letters, 24 (2014) 799-807.

[4] XI Ning, LI Zhuo, WANG Tingjin, et al. PI3 kinase modulators and methods of use. Patent WO2014022128A(1).(2014).

[5] Mugnaini Claudia, Falciani Chiara, Derosa Maria. Regioselective functionalization of quinolin4(1H)-ones via sequential palladium-catalyzed reactions, J. Tetrahedron Lett, 67(2011) 5776-5783.

[6] Ma,Menglin, Huang,Jianbiao, et al. Syntheses of 4-(1H)-quinolones and the brominated or methoxy substituted derivatives, J. Youji Huaxue, 33(2013) 378-382.

[7] Ai Jeng Lin, Ti Li Loo. Synthesis and Antitumor Activity of Halogen-Substituted 4-(3,3-di-

Methyl-1-triazeno)quinoline, J. Journal of Medicinal Chemistry, 21 (1978) 268-271.

[8] REN,Pingda,LIU,Yi,et al. Heterocyclic compounds and uses thereof. Patent WO2011022439 A(1). (2011).

[9] Duffy,Kevin J, Chai,Deping, et al. Preparation of quinolinylmethylidene thiazolone derivatives as hYAK3 proteins inhibitors. Patent WO 2006132739A(2). (2006). 